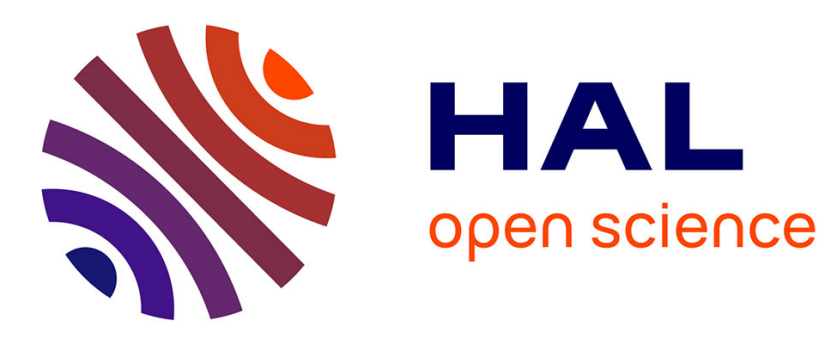

\title{
Hot fuel element thermal-hydraulics in the Jules Horowitz Reactor
}

\author{
R. Pegonen, S. Bourdon, C. Gonnier, H. Anglart
}

\section{To cite this version:}

R. Pegonen, S. Bourdon, C. Gonnier, H. Anglart. Hot fuel element thermal-hydraulics in the Jules Horowitz Reactor. Nuclear Engineering and Design, 2016, 300, pp.149-160. 10.1016/j.nucengdes.2016.01.031 . cea-02385804

\section{HAL Id: cea-02385804 https://hal-cea.archives-ouvertes.fr/cea-02385804}

Submitted on 29 Nov 2019

HAL is a multi-disciplinary open access archive for the deposit and dissemination of scientific research documents, whether they are published or not. The documents may come from teaching and research institutions in France or abroad, or from public or private research centers.
L'archive ouverte pluridisciplinaire HAL, est destinée au dépôt et à la diffusion de documents scientifiques de niveau recherche, publiés ou non, émanant des établissements d'enseignement et de recherche français ou étrangers, des laboratoires publics ou privés. 


\title{
Hot fuel element thermal-hydraulics in the Jules Horowitz Reactor
}

\author{
R. Pegonen ${ }^{\mathrm{a}, *}$, S. Bourdon ${ }^{\mathrm{b}}$, C. Gonnier ${ }^{\mathrm{b}}, \mathrm{H}$. Anglart $^{\mathrm{a}}$ \\ ${ }^{a}$ KTH Royal Institute of Technology, Roslagstullsbacken 21, SE-10691 Stockholm, Sweden \\ ${ }^{b}$ CEA, DEN, DER, SRJH, CEA Cadarache, 13108 Saint-Paul-lez-Durance Cedex, France
}

\begin{abstract}
The newest European high performance material testing reactor, the Jules Horowitz Reactor, will support existing and future nuclear reactor designs. The reactor is under construction at CEA Cadarache research center in France and is expected to start operation at the end of this decade. This paper presents the Computational Fluid Dynamics simulation of the reactors hot fuel element. Moreover conjugate heat transfer analysis is performed for the hot channel. The main objective of this work is to improve the thermal-hydraulic knowledge of the complex hot fuel element and to present the most prominent finds. Possible improvements for the future work are suggested.
\end{abstract}

Keywords: Jules Horowitz Reactor, STAR-CCM+, RANS, Hot fuel element, Hot channel.

\section{Introduction}

Europe needs at least one new material testing reactor (MTR) for exchanging the current over half a century old aging fleet. The newest European MTR, the Jules Horowitz Reactor (JHR), meets the newest safety standards in nuclear industry and is under construction in France and it is expected to start operation at the end of this decade.

The JHR unique design and the current thermalhydraulic modeling methodology is described in Pegonen et al. (2014a). The CEA (Alternative and Atomic Energy Commission) methodology is used to analyze the thermal-hydraulic calculation of the reactor during the loss of flow accident and the future improvement possibilities are listed.

This paper is a second step of an ongoing four year project aiming at development of an improved JHR CATHARE2 model. The aim of this paper is to present the thermal-hydraulics around the JHR hot fuel element in the rack through the Computational Fluid Dynamics (CFD) simulation. A conjugate heat transfer calculation is carried out for the hot channel and its surrounding fuel plates and stiffeners.

This paper first gives a succinct overview of the JHR and describes the computational model. Next a thermalhydraulic analysis of the flow within the JHR hot fuel

\footnotetext{
${ }^{*}$ Corresponding author at: CEA Cadarache, 13108 Saint-Paul-lezDurance Cedex, France. Tel.: +33 442253236.

Email address: pegonen@kth.se (R. Pegonen)
}

element is performed. Finally, some improvements for the future work are proposed.

\section{The Jules Horowitz Reactor}

The Jules Horowitz Reactor is a new highperformance material-testing reactor currently under construction at the CEA in Cadarache, France. The JHR project involves several European and international partners. This pool-type reactor will have maximum core power of $100 \mathrm{MW}_{t h}$ and it will use light water for cooling and for moderation (CEA, 2013).

The JHR will be used to investigate the behavior of nuclear materials and fuels under irradiation and to produce radioisotopes for medical purposes (e.g. ${ }^{99} \mathrm{Mo}$ ) (Dupuy et al., 2005, Bignan et al., 2011). The reactor's flexible high-performance experimental capacity will meet industry's needs related to generations II, III and IV nuclear reactors and will allow about 20 simultaneous experiments (Iracane et al., 2008). The JHR will provide a high neutron flux- twice as large as the maximum available today in European MTRs (Bignan et al., 2011).

\section{Computational Model}

In this work the modeling process comprised of four stages which included creating the complex solid-liquid computer-aided design (CAD) models, generating the 
computational meshing, setting up and running the simulation, and post-processing the results. The first stage was conducted by utilizing the commercial CAD software SolidWorks and other stages were carried out by using the commercial CFD code STAR-CCM+.

For this research the following CAD models were created: (i) the water geometry between the fuel plates with simplified annular inlet and outlet, (ii) the water geometry of the fuel element inside the rack, and (iii) the hot channel's assembly (water + metal parts). The exact geometry description is given in the next section. The purpose of the first geometry is to simulate the conditions in the center of the fuel assembly, uninfluenced by the top end cap and the bottom end cap. The second geometry broadens our understanding of the conditions in the hot fuel assembly and deduces the boundary conditions for the third geometry utilized to evaluate the conditions in the hot channel.

The study examines cold conditions (water temperature is $32.1{ }^{\circ} \mathrm{C}$, without power) and nominal operational conditions (with power) in the JHR hot fuel element.

The step-wise approach was used during the steadystate calculations. First the constant density simulation was carried out, then the cold conditions were simulated by adding the IAPWS-IF97 water properties. In the last step power table/functions were included to perform simulation with the nominal operating conditions.

In all the simulations except from the hot channel's calculation there is only a fluid region and it is assumed to be three dimensional, steady and turbulent. Segregated flow, segregated fluid temperature, realizable $k-\epsilon$ turbulence model, and gravity physical models as well as two-layer all $y+$ wall treatment are used. The last is designed to give accurate results regardless of the sublayer of the turbulent boundary layer in which the nearwall centroid is located in.

In the hot channel's simulation each metal part has a separate region and they are assumed to have constant density and to be three dimensional and steady, furthermore segregated energy model is utilized.

\subsection{Geometry}

\subsubsection{The JHR fuel element}

The reactor has 34 to 37 fuel elements located in an aluminum rack. Each fuel element consists of eight circular rings of curved fuel plates $(1.37 \mathrm{~mm}$ thick) assembled with three Al 6061-T6 stiffeners, see Fig. 1 The fuel assembly has external diameter of $97.7 \mathrm{~mm}$ and the hydraulic gap between fuel plates is $1.95 \mathrm{~mm}$ wide. There is $\varnothing \approx 40 \mathrm{~mm}$ central hole to host: (i) the guide tube filled by the control rod or by the Al rod, (ii) the protection tube and the experimental device.
Each fuel plate comprises of AlFeNi cladding, $\mathrm{U}_{3} \mathrm{Si}_{2} / \mathrm{Al}$ fuel and borated aluminum poison at the top end of the fuel element. The thickness of the fuel meat and the poison layer is $0.61 \mathrm{~mm}$ (Dupuy et al. 2005). The total height of the fuel plate is $700 \mathrm{~mm}$ from which $600 \mathrm{~mm}$ is the fuel zone and $30 \mathrm{~mm}$ is the poison zone in the upper part. The overall height of the fuel element is $1015 \mathrm{~mm}$. The top end cap and the bottom end cap have the lengths of $115 \mathrm{~mm}$ and $145 \mathrm{~mm}$, respectively.

\subsubsection{CAD geometry}

The design of the geometry used in this work is based on the 2011 technical drawing of the JHR fuel element (AREVA TA, 2011). Compared to the original drawings some minor simplifications had to be made for more suitable CFD model. During the simplifications, extremely small irrelevant details/gaps were neglected in order to maintain reasonable mesh cell count.

The hot channel's geometry assembly, see Fig. 2(a), represents the second water channel from the center of fuel assembly with its surrounding structural materials and consists of nine parts: the water, the inner and the outer cladding/fuel/poison and two stiffeners. Except from the water channel only symmetric one half of the parts, associated to the channel, are modeled. The overall height of the assembly is $700 \mathrm{~mm}$.

In the case of the second geometry, see Fig. 2(b), 50 $\mathrm{mm}$ annulus was added to the both ends of the water geometry between fuel plates and the rack. The total height of the geometry is $800 \mathrm{~mm}$. In the case of the third geometry, water between the fuel assembly and the rack, see Fig. 2. (c-d), the geometries inlet was prolonged by $10 \mathrm{~mm}$ annulus for the numerical reason and the total height of the geometry is $1078 \mathrm{~mm}$. The complexity of the third geometry is displayed by the cross-sectional areas plotted in Fig. 3 .

It is impossible to model only one part of the geometry due to the asymmetry of the fuel assembly and of the thermal-hydraulic conditions.

\subsection{Mesh}

The current best practice is to utilize a conformal mesh for conjugate heat transfer and it can be only created by polyhedral mesher (CD-adapco, 2012). Furthermore the meshing procedure for the complex geometry (fuel assembly) should be fully automatic to produce optimal mesh and to save time. Therefore in this study unstructured polyhedral mesh with surface remesher and prism layers (except from the solids) was used with every geometry. Although with the second and with the third geometries, see Fig. 2(b-d), there was 


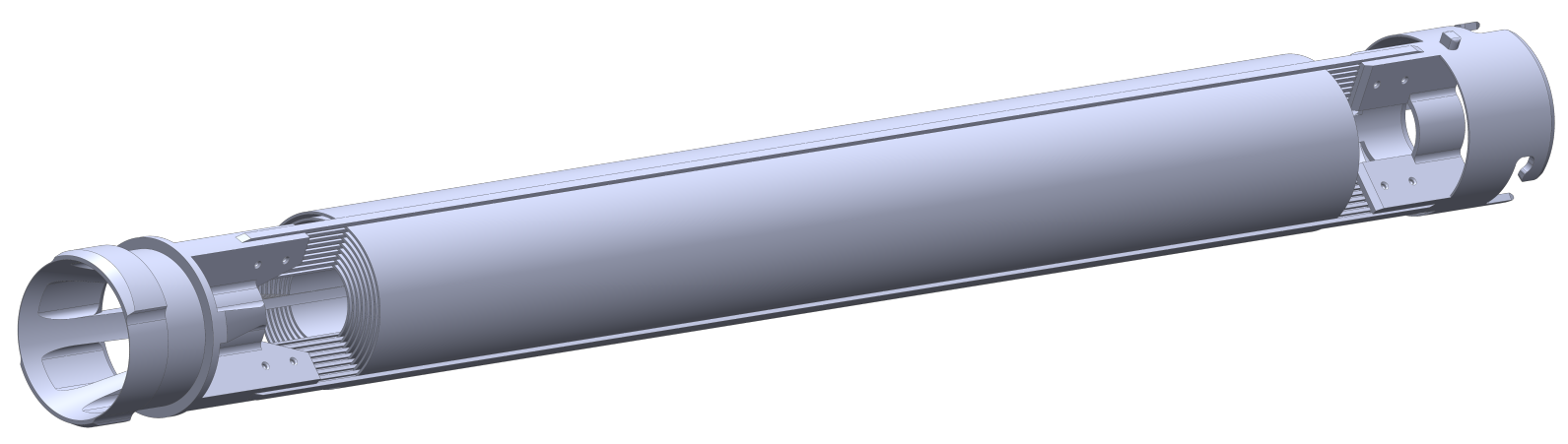

Figure 1: Isometric view of the JHR fuel element.

no direct necessity to utilize polyhedral grid, it was done for consistency.

A major advantage of polyhedral cells is that due to numerous neighbors, gradients can be better approximated in a complex geometry as well as cells are less sensitive to stretching and are favorable for handling recirculating flows (Peric, 2004). Compared to tetrahedral meshes one needs about four time less cells, about two times less memory and about $10-20 \%$ of computing time to reach the same accuracy (Peric, 2004).

Computational requirements for meshing the geometries are substantial. In rough conservative estimation it is assumed that it requires about 1 GB of RAM to generate one million polyhedral cells. Accordingly it was reckoned that the maximum number of cells that can be produced is around 24-26 million cells.

Three final meshes, one for each geometry, was created and the total number of cells is presented in Table 1. The number of cells was picked to have the most cells computationally available (limited by the RAM) for the best possible resolution. Two sets of meshing reference values were used: finer values for the mesh 1 and identical coarser values for mesh 2 and 3, see Table 1 . There were five prism layers along the walls in the fluid domain to resolve the boundary layer and it is considered sufficient when wall functions are included (CD-adapco, 2013).

In order to get good quality volume mesh, a surface mesh must be free of errors and contain valid elements. Mesh quality can be described by assessing the face validity and the volume change of the cell. The first is an area-weighted measure of the correctness of the face normals relative to their attached cell centroid and the value 1.0 means that all face normals are correctly pointing away from the cell centroid (CD-adapco, 2013). Values lower than 0.5 point out a negative volume cell. At the same time the volume change metric describes the ratio of the volume of a cell to that of its largest neighbor and the cells with a value of $10^{-5}$ or below should be investigated further (CD-adapco, 2013). In all three grids generated the face validity overall value was 1.0 and the volume change had values above 0.001 and most of the cells above 0.1 , see Table 1

\subsubsection{Mesh sensitivity study}

To study the influence of the mesh size several meshes of the third geometry were automatically created by using the same topology by just reducing the base size from $6 \mathrm{~mm}$ to $3 \mathrm{~mm}$ and by creating meshes from $8,516,491$ cells to $23,211,863$ cells. The prism layers physics were left unaltered by specifying its parameters in absolute rather than relative terms. As a convergence criterion the overall pressure drop was monitored with different meshes. It was observed that by utilizing the mesh larger than 16.5 million cells the total pressure drop varies less than $0.3 \%$ compared to the finest mesh. Although mesh with 16.5 million cells would have been sufficient, the finest mesh was chosen for the simulation.

The second geometry represents the center part of the third geometry as well as the first geometry is modeling only its channel including the solid parts. Therefore it is valid to use identical meshing parameters for meshing geometries two and three. In case of the first geometry the finest mesh possible was generated.

\subsection{Governing equations}

The steady-state Navier-Stokes equations for Reynolds-averaged turbulent compressible flows (also named as the Favre-averaged Navier-Stokes equations) can be written as (Wilcox, 2006):

$$
\begin{gathered}
\frac{\partial}{\partial x_{i}}\left(\bar{\rho} \bar{v}_{i}\right)=0 \\
\frac{\partial}{\partial x_{j}}\left(\bar{\rho} \bar{v}_{i} \bar{v}_{j}\right)=-\frac{\partial \bar{p}}{\partial x_{i}}+\frac{\partial \tau_{i j}}{\partial x_{j}}+F_{i},
\end{gathered}
$$


Table 1: Mesh information

\begin{tabular}{|c|c|c|c|c|c|c|c|c|c|}
\hline \multirow[b]{3}{*}{ Water } & \multicolumn{3}{|c|}{ Mesh 1 for geometry in Fig. 2 a) } & \multicolumn{3}{|c|}{ Mesh 2 for geometry in Fig. 2 b) } & \multicolumn{3}{|c|}{ Mesh 3 for geometry in Fig. 2 (c-d) } \\
\hline & Cells & Faces & Vol.Ch $\geq 0.1$ & Cells & Faces & Vol.Ch $\geq 0.1$ & Cells & Faces & Vol.Ch $\geq 0.1$ \\
\hline & $11,110,954$ & $51,853,736$ & $98.818 \%$ & $22,338,987$ & $92,714,823$ & $99.770 \%$ & $23,211,863$ & $96,899,148$ & $99.472 \%$ \\
\hline Cladding $_{1}$ & $2,084,863$ & $10,871,080$ & $99.190 \%$ & - & - & - & - & - & - \\
\hline Cladding $_{2}$ & $2,219,125$ & $11,566,052$ & $99.255 \%$ & - & - & - & - & - & - \\
\hline Fuel $_{1}$ & $1,427,151$ & $7,423,714$ & $99.147 \%$ & - & - & - & - & - & - \\
\hline $\mathrm{Fuel}_{2}$ & $1,585,793$ & $8,249,086$ & $99.144 \%$ & - & - & - & - & - & - \\
\hline Poison $_{1}$ & 71,808 & 372,594 & $98.999 \%$ & - & - & - & - & - & - \\
\hline Poison $_{2}$ & 79,780 & 413,264 & $99.282 \%$ & - & - & - & - & - & - \\
\hline Stiffener $_{1}$ & 325,485 & $1,805,268$ & $96.848 \%$ & - & - & - & - & - & - \\
\hline Stiffener $_{2}$ & 327,565 & $1,818,713$ & $96.824 \%$ & - & - & - & - & - & - \\
\hline & Layers & Abs. size & Stretching f. & Layers & Abs. size & Stretching f. & Layers & Abs. size & Stretching $\mathrm{f}$. \\
\hline Prism layer & 5 & $0.295 \mathrm{~mm}$ & 1.0 & 5 & $0.6 \mathrm{~mm}$ & 1.0 & 5 & $0.6 \mathrm{~mm}$ & 1.0 \\
\hline Base size & & $2 \mathrm{~mm}$ & & & $3 \mathrm{~mm}$ & & & $3 \mathrm{~mm}$ & \\
\hline
\end{tabular}

where $v$ is the velocity, $\rho$ is the density, $p$ is the pressure, $F$ is the specific total body force and $\tau$ is the stress tensor:

$$
\tau_{i j}=\mu\left(\frac{\partial \bar{v}_{i}}{\partial x_{j}}+\frac{\partial \bar{v}_{j}}{\partial x_{i}}-\frac{2}{3} \frac{\partial \overline{v_{k}}}{\partial x_{k}} \delta_{i j}\right)-\overline{\rho v_{i}^{\prime} v_{j}^{\prime}},
$$

where $\mu$ is the dynamic viscosity. The first part of $\tau$ represents the viscous stress tensor and $-\overline{\rho v_{i}^{\prime} v_{j}^{\prime}}$ is the Reynolds stress tensor and can be evaluated by using the Boussinesq assumption (Boussinesq, 1877, Pegonen et al. 2014b):

$$
-\overline{\rho v_{i}^{\prime} v_{j}^{\prime}}=\mu_{t}\left(\frac{\partial \bar{v}_{i}}{\partial x_{j}}+\frac{\partial \bar{v}_{j}}{\partial x_{i}}-\frac{2}{3} \frac{\partial \overline{v_{k}}}{\partial x_{k}} \delta_{i j}\right)-\frac{2}{3} \bar{\rho} k_{t} \delta_{i j},
$$

where $\mu_{t}$ is the turbulence dynamic viscosity and $k_{t}$ is the specific turbulent kinetic energy. The steady-state Reynolds-averaged energy equations for the fluid (Eq. 5) and for the solid (Eq. 6) are expressed as (GallegosMuñoz et al., 2012, Wilcox, 2006):

$$
\begin{aligned}
\frac{\partial}{\partial x_{i}}\left(c_{p} \bar{\rho} \bar{v}_{i} \bar{T}\right)= & \frac{\partial}{\partial x_{i}}\left(c_{p} \frac{\mu}{\operatorname{Pr}} \frac{\partial \bar{T}}{\partial x_{i}}+c_{p} \overline{\rho v_{i}^{\prime} T^{\prime}}\right)+\mu \phi+\dot{q}, \\
& \frac{\partial}{\partial x_{i}}\left(\lambda_{S} \frac{\partial \bar{T}_{S}}{\partial x_{i}}\right)+\dot{q_{S}}=0,
\end{aligned}
$$

where $c_{p}$ is the specific heat, $T$ is the fluid temperature, $\operatorname{Pr}$ is the Prandtl number, $\lambda_{S}$ is the solid thermal conductivity, $T_{S}$ is the solid temperature, $\dot{q}$ and $\dot{q}_{S}$ are the power density sources for the fluid and the solid, respectively. In Eq. $5 c_{p} \overline{\rho v_{i}^{\prime} T^{\prime}}$ corresponds to the turbulent heat flux and $\mu \phi$ is the viscous heating dissipation. In this paper realizable $k-\epsilon$ turbulence model (Shih et al., 1994) were utilized. Compared to the standard $k-\epsilon$ turbulence model, it uses non-constant $C_{\mu}$ variable in the turbulence dynamic viscosity $\left(\mu_{t}\right)$ formula:

$$
\mu_{t}=\rho C_{\mu} \frac{k_{t}^{2}}{\epsilon}
$$

and there is a new transport equation (Eq. 9p for the kinetic energy dissipation rate $(\epsilon)$ :

$$
\begin{aligned}
\frac{\partial}{\partial x_{j}}\left(\rho k_{t} v_{j}\right)= & \frac{\partial}{\partial x_{j}}\left(\left(\mu+\frac{\mu_{t}}{\sigma_{k}}\right) \frac{\partial k_{t}}{\partial x_{j}}\right)+ \\
& +P_{k}+P_{b}+D_{d}-\rho \epsilon
\end{aligned}
$$

$$
\begin{aligned}
\frac{\partial}{\partial x_{j}}\left(\rho \epsilon v_{j}\right)= & \frac{\partial}{\partial x_{j}}\left(\left(\mu+\frac{\mu_{t}}{\sigma_{\epsilon}}\right) \frac{\partial \epsilon}{\partial x_{j}}\right)+\rho C_{1} S \epsilon- \\
& -\rho C_{2} \frac{\epsilon^{2}}{k_{t}+\sqrt{\mu \epsilon / \rho}}+C_{1 \epsilon} \frac{\epsilon}{k_{t}} C_{3 \epsilon} P_{b},
\end{aligned}
$$

where $\sigma$ is the Schmidt number, $P_{k}$ and $P_{b}$ represent $k_{t}$ production due to mean velocity gradients and buoyancy, $D_{d}$ represents the dilatation dissipation, $C_{1}=\max [0.43, \eta /(\eta+5)], \eta=S k / \epsilon, S=\sqrt{2 S_{i j} S_{i j}}, S_{i j}=$ $1 / 2\left(\partial v_{i} / \partial x_{j}+\partial v_{j} / \partial x_{i}\right), C_{1 \epsilon}=1.44, C_{2}=1.9, \sigma_{k}=1.0$ and $\sigma_{\epsilon}=1.2$.

\subsection{Modeling assumptions}

The following are the assumptions made in this study:

- The CEA 36 assembly JHR core reference power is 108.77 MW (Pegonen et al., 2014a), from which 


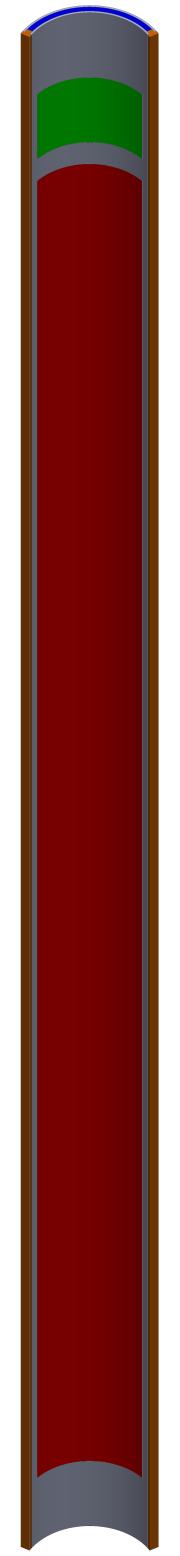

(a)

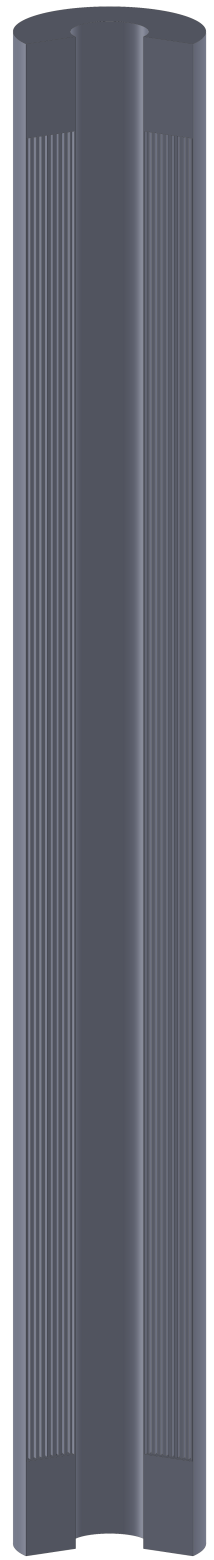

(b)
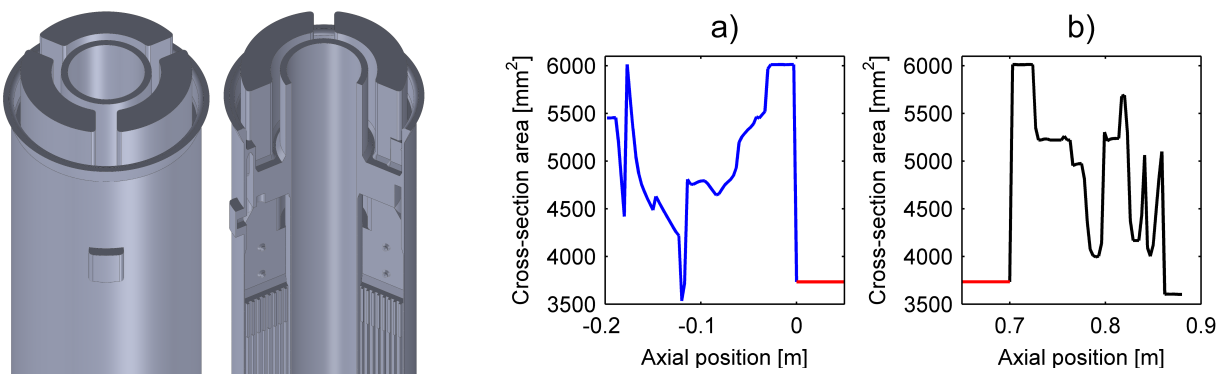

Figure 3: Cross-section areas of the flow surrounding the bottom end cap (a) and the top end cap (b). Red color marks flow cross-section area through the fuel plates.

with the factor 1.79 compared to the mean values. Similar factor is used in the CEA safety analysis. In addition it is assumed that only the fuel meat and the water are the source of power.

- Taking into account the power distribution, the hot channel is the second channel from the center of the fuel assembly in the hot sector.

- In the hot channel calculation it is assumed that both fuel plates contribute $1 / 2$ of the power into the hot channel: $78.2 \mathrm{~kW}$ from the first and 85.0 $\mathrm{kW}$ from the second fuel plate. In addition $6.3 \mathrm{~kW}$ is the power in water due to neutrons and gamma rays.

- All parts are considered geometrically new and no manufacturing tolerances or operational effects (oxidation, swelling, etc.) on the fuel plate are taken into account.

- The total mass flow rate in the core is $1546.4 \mathrm{~kg} / \mathrm{s}$, from which $42.955 \mathrm{~kg} / \mathrm{s}(1 / 36 \mathrm{th})$ is assumed to flow through the hot fuel element.

\subsection{Material properties}

The material properties used in the CFD simulations are summarized in Table 2 The thermodynamic properties of the water are obtained from the IAPWS-IF97 (International Association for the Properties of Water and Steam- Industrial Formulation 1997) formulation provided in STAR-CCM+. For the cladding and the fuel same constant values and temperature dependent functions as in the FLICA4 calculation described in Pegonen et al. (2014a) are utilized. Material properties for borated $\mathrm{Al}$ poison and for $\mathrm{Al}$ 6061-T6 stiffeners are taken from NRC (2001) and ASM Aerospace Specification Metals, Inc. (2015), respectively.
$5.145 \mathrm{MW}$ is the total power of the hot fuel element and $0.264 \mathrm{MW}$ is the power in the water, in the hot channel, originating from neutron moderation and gamma heating. In here it is assumed that the hot assembly and the water in it have the power 
Table 2: Material properties

\begin{tabular}{llllll}
\hline Property & $\mathrm{U}_{3} \mathrm{Si}_{2} / \mathrm{Al}$ fuel & AlFeNi cladding & Al 6061-T6 stiffener & Borated Al poison & Water \\
\hline$\rho\left[\mathrm{kg} / \mathrm{m}^{3}\right]$ & 5753 & 2745 & 2700 & 2658 & IAPWS-IF97 \\
$c_{p}[\mathrm{~J} / \mathrm{kg} / \mathrm{K}]$ & $0.0833 \cdot \mathrm{T}_{C}+338$ & $0.808569 \cdot \mathrm{T}_{C}+2632.34 / \mathrm{T}_{C}+762.132$ & 896 & 896 & IAPWS-IF97 \\
$\lambda[\mathrm{W} / \mathrm{m} / \mathrm{K}]$ & 10 & $1.4604 \cdot 10^{-3} \cdot \mathrm{T}_{C}-6.8700 \cdot 10^{-7} \cdot \mathrm{T}_{C}^{2}+13.668$ & 167 & 145 & IAPWS-IF97 \\
\hline \multicolumn{2}{c}{$\mathrm{T}_{C^{-}}$temperature in ${ }^{\circ} \mathrm{C}$}
\end{tabular}

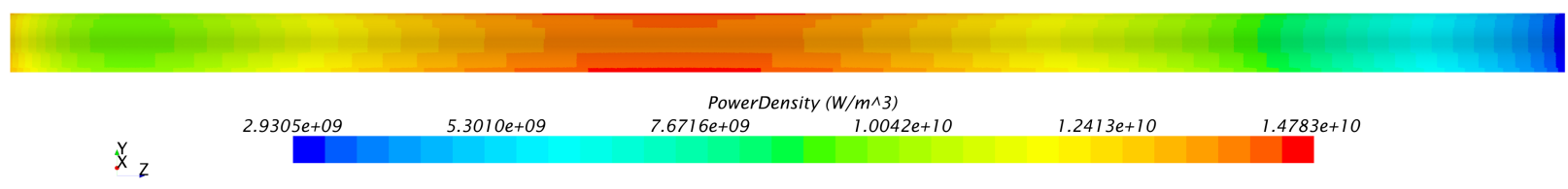

Figure 4: Power density distribution in the first fuel plate meat in the hot channel calculation. Flow direction is from the left to the right and fuel meat is seen from the center of the fuel assembly.

\subsection{Power distribution}

Fuel power distribution profile for the hot fuel assembly is obtained from the CEA's 36 assembly JHR core power distribution neutronic calculation (Pouchin. 2013). From these data points the following were created: (i) a volumetric power distribution function for the both fuel plate meats in the hot channel calculation, and (ii) a surface power table containing 14,257 points for simulations involving only the water geometry. The power table is created in a way that during the simulation a specific locations obtains its value from the closest data point without interpolating. Walls that correspond to the axial height of the fuel meat have nonzero surface power. Power density in the first fuel meat in the hot channel simulation can be seen in Fig. 4

For describing the water power originating form neutron moderation and gamma heating a simplified approach is used. A full core thermal neutron flux axial profile (Sireta 2014) is utilized for generating power density function and 143 points table. Both are used similarly as described above and both are only axially dependent.

\subsection{Convergence}

Steady-state convergence was established after the following was fulfilled:

- All normalized residuals (continuity, mass, energy, turbulent kinetic energy and turbulent dissipation rate) have reached the desired values or they do not change with additional iterations.
- Monitored key physical parameters and quantities of interest should "flatten out" in order to be confident that the solution is converged (Kuron, 2015).

\subsection{Boundary conditions}

Except from the third geometry, all the geometries have one inlet, located at the bottom, and one outlet, located at the top, see Fig. 2. The second geometry outlet geometrically consists of four separate surfaces that are merged into one outlet surface while defining physical conditions.

Identical initial and boundary conditions are employed for the second and the third geometry. A mass flow of $42.955 \mathrm{~kg} / \mathrm{s}$, a total temperature of $32.1^{\circ} \mathrm{C}$, a turbulence intensity of 0.03 with a length scale of $3 \mathrm{~mm}$ were specified on the mass flow inlets. At the same time the pressure outlet had the following values: a static pressure of $0 \mathrm{~Pa}$, a turbulence intensity of 0.03 and a turbulence length scale of $3 \mathrm{~mm}$. The no-slip smooth walls thermal conditions were imposed by heat flux obtained from the table described above.

In every simulation a reference pressure is adjusted to have an area-averaged pressure $600939 \mathrm{~Pa}$ at $\mathrm{z}=$ $0.7 \mathrm{~m}$. Pressure value is obtained from the system code CATHARE simulation, described in Pegonen et al. (2014a), where the full JHR with the simplified approach for the core is calculated.

The liquid region of the first geometry has similar inlet and outlet boundary conditions as described above, only the inlet mass flow rate is $0.924 \mathrm{~kg} / \mathrm{s}$ (see Table 4) and the turbulence length scale is $0.374 \mathrm{~mm}$. Furthermore the smooth non-slip walls were specified to have adiabatic thermal conditions. To allow conjugate heat 
transfer between different regions a contact interface is utilized to connect fluid/solid and solid/solid regions.

\section{Results and Discussion}

\subsection{Mass flow distribution}

\subsubsection{Cold condition}

As a starting point a hand calculation was performed to evaluated the mass flow split in the cold conditions $\left(32.1^{\circ} \mathrm{C}\right)$ between the fuel plates in $1 / 3$ symmetric geometry by utilizing Darcy-Weisbach equation:

$$
\Delta p_{\text {loss }, \text { friction }}=f_{D} \frac{L}{D_{h}} \frac{1}{2} \rho v^{2},
$$

where $f_{D}$ is the Darcy's friction coefficient, $L$ is the length, $D_{h}$ is the hydraulic diameter. Darcy's friction coefficient was evaluated by using the Colebrook (Eq. 11 and the Blasius (Eq. 12) equations for pipes:

$$
\begin{gathered}
\frac{1}{\sqrt{f_{D}}}=-2 \log _{10}\left(\frac{\varepsilon}{3.7 D_{h}}+\frac{2.51}{\operatorname{Re} \sqrt{f_{D}}}\right), \\
f_{D}=\frac{0.316}{R e^{0.25}},
\end{gathered}
$$

where $\varepsilon$ is the roughness height and $R e$ is the Reynolds number. Cold conditions are examined in order to eliminate the change of the flow distribution that may arise from power distribution.

Flow distribution obtained by using Colebrook or Blasius equations differ less than $0.6 \%$, see Table 3 Both correlations underestimate mass flow rate in the inner channels and overestimate it in the outer channels, compared to the CFD calculation, therefore a correction factors should be utilized while using pipe correlations for estimating mass flow rates in the JHR geometry.

By comparing the mass flow rate average values obtained with the second and the third geometries one can notice that the bottom end cap and the top end cap influence the flow field by reducing mass flow through the first five channels and by increasing it in the last four channels. The highest averaged loss is observed in the second channel $(-5.9 \%)$ and the largest gain in the eighth channel $(+3.9 \%)$, see Table 3 Reduction in the hot channel (channel 2, sector 2) is $6.8 \%$ from 0.987 $\mathrm{kg} / \mathrm{s}$ to $0.919 \mathrm{~kg} / \mathrm{s}$, see Table 4

There is a deviation between the mass flow rates obtained in the CFD simulation and those based on the Blasius and the Colebrook correlations. From Table 3 it can be observed that in the cold conditions, the Blasius correlation over-estimates the averaged mass flow rate in the second channel by $4.1 \%$ (0.969 vs 0.929$)$ and the Colebrook correlation by $4.6 \%$ (0.974 vs 0.929 ).

The mass flow split obtained by assuming constant mass flux $(G)$ is added into the Table 3 as most inaccu-

\begin{tabular}{|c|c|c|c|c|c|c|c|c|c|}
\hline \multirow[b]{2}{*}{ Ch. } & \multicolumn{6}{|c|}{ Cold condition $\left(32.1^{\circ} \mathrm{C}\right)$} & \multicolumn{3}{|c|}{ Nominal condition } \\
\hline & Const. G & Colebrook & Blasius & 2 geom. & 3 geom. & $\Delta_{23}$ & 2 geom. & 3 geom. & $\Delta_{23}$ \\
\hline 1 & 0.933 & 0.861 & 0.857 & 0.883 & $\overline{0.837}$ & $-5.2 \%$ & 0.878 & 0.829 & $-5.6 \%$ \\
\hline 2 & 1.020 & 0.974 & 0.969 & 0.987 & 0.929 & $-5.9 \%$ & 0.995 & 0.935 & $-6.0 \%$ \\
\hline 3 & 1.176 & 1.126 & 1.121 & 1.134 & 1.075 & $-5.2 \%$ & 1.142 & 1.081 & $-5.3 \%$ \\
\hline 4 & 1.332 & 1.278 & 1.273 & 1.281 & 1.239 & $-3.2 \%$ & 1.288 & 1.246 & $-3.3 \%$ \\
\hline 5 & 1.488 & 1.432 & 1.425 & 1.437 & 1.420 & $-1.2 \%$ & 1.445 & 1.429 & $-1.1 \%$ \\
\hline 6 & 1.644 & 1.586 & 1.579 & 1.600 & 1.608 & $+0.5 \%$ & 1.607 & 1.619 & $+0.7 \%$ \\
\hline 7 & 1.800 & 1.739 & 1.732 & 1.757 & 1.802 & $+2.6 \%$ & 1.769 & 1.815 & $+2.6 \%$ \\
\hline 8 & 1.956 & 1.893 & 1.885 & 1.917 & 1.991 & $+3.9 \%$ & 1.930 & 2.006 & $+3.9 \%$ \\
\hline 9 & 2.967 & 3.432 & 3.441 & 3.318 & 3.416 & $+3.0 \%$ & 3.263 & 3.357 & $+2.9 \%$ \\
\hline
\end{tabular}
rate method of discussed.

Table 3: Average mass flow rates $[\mathrm{kg} / \mathrm{s}]$

\subsubsection{Nominal condition}

Similar tendencies as described above were observed also under nominal condition. Here the highest averaged loss in the second channel is $-6.0 \%$ and the largest gain in the eighth channel is $+3.9 \%$, see Table 3 . Reduction in the hot channel is $7.2 \%$ from $0.996 \mathrm{~kg} / \mathrm{s}$ to $0.924 \mathrm{~kg} / \mathrm{s}$, see Table 4

Next the change in the mass flow distribution was compared between the cold conditions and the nominal conditions. As expected it is observed that the mass flow is reduced from the first and the last channels and increased in others, see Table 5. It can be explained by the fact that these two channels are heated only from one side in comparison to the central channels.

Table 5: The change of the averaged mass flow rates due to the power distribution

\begin{tabular}{llllllllll}
\hline Ch. & 1 & 2 & 3 & 4 & 5 & 6 & 7 & 8 & 9 \\
\cline { 2 - 9 }$\Delta_{2 \text { Geom }}$ & $-0.6 \%$ & $+0.8 \%$ & $+0.7 \%$ & $+0.6 \%$ & $+0.6 \%$ & $+0.4 \%$ & $+0.7 \%$ & $+0.7 \%$ & $-1.7 \%$ \\
$\Delta_{3 \text { Geom }}$ & $-1.0 \%$ & $+0.7 \%$ & $+0.6 \%$ & $+0.6 \%$ & $+0.6 \%$ & $+0.7 \%$ & $+0.7 \%$ & $+0.8 \%$ & $-1.7 \%$
\end{tabular}

\subsubsection{Mass flow in the hot sector}

In the first six channels of the hot sector (Sector 2, Table 4) the mass flows are under the average values and in the last three over the average values. Nominal mass flow rate for the hot channel is $0.924 \mathrm{~kg} / \mathrm{s}$ and its velocity distribution at the axial location where the power density peaks is shown in Fig. 5 . 
Table 4: Mass flow rates $[\mathrm{kg} / \mathrm{s}]$

\begin{tabular}{|c|c|c|c|c|c|c|c|c|c|c|c|c|}
\hline \multirow[b]{3}{*}{ Ch. } & \multicolumn{6}{|c|}{ Second geometry, see Fig. 2bb) } & \multicolumn{6}{|c|}{ Third geometry, see Fig. 2(c-d) } \\
\hline & \multicolumn{3}{|c|}{ Cold conditions $\left(32.1^{\circ} \mathrm{C}\right)$} & \multicolumn{3}{|c|}{ Nominal conditions } & \multicolumn{3}{|c|}{ Cold conditions $\left(32.1^{\circ} \mathrm{C}\right)$} & \multicolumn{3}{|c|}{ Nominal conditions } \\
\hline & Sector 1 & Sector 2 & Sector 3 & Sector 1 & Sector 2 & Sector 3 & Sector 1 & Sector 2 & Sector 3 & Sector 1 & Sector 2 & Sector 3 \\
\hline 1 & 0.884 & 0.884 & 0.883 & 0.878 & 0.879 & 0.877 & 0.840 & 0.832 & 0.838 & 0.833 & 0.824 & 0.830 \\
\hline 2 & 0.986 & 0.987 & 0.987 & 0.993 & 0.996 & 0.996 & 0.937 & 0.919 & 0.933 & 0.941 & 0.924 & 0.939 \\
\hline 3 & 1.131 & 1.132 & 1.140 & 1.138 & 1.141 & 1.148 & 1.082 & 1.066 & 1.078 & 1.087 & 1.072 & 1.084 \\
\hline 4 & 1.276 & 1.274 & 1.291 & 1.281 & 1.282 & 1.300 & 1.246 & 1.228 & 1.242 & 1.252 & 1.236 & 1.249 \\
\hline 5 & 1.434 & 1.434 & 1.444 & 1.439 & 1.442 & 1.454 & 1.426 & 1.408 & 1.428 & 1.432 & 1.418 & 1.437 \\
\hline 6 & 1.600 & 1.601 & 1.598 & 1.603 & 1.609 & 1.609 & 1.613 & 1.597 & 1.614 & 1.620 & 1.610 & 1.626 \\
\hline 7 & 1.757 & 1.760 & 1.756 & 1.764 & 1.773 & 1.769 & 1.799 & 1.800 & 1.807 & 1.807 & 1.816 & 1.821 \\
\hline 8 & 1.917 & 1.918 & 1.917 & 1.923 & 1.935 & 1.933 & 1.987 & 2.003 & 1.984 & 1.995 & 2.023 & 2.001 \\
\hline 9 & 3.318 & 3.314 & 3.322 & 3.260 & 3.266 & 3.264 & 3.395 & 3.461 & 3.394 & 3.332 & 3.404 & 3.334 \\
\hline
\end{tabular}

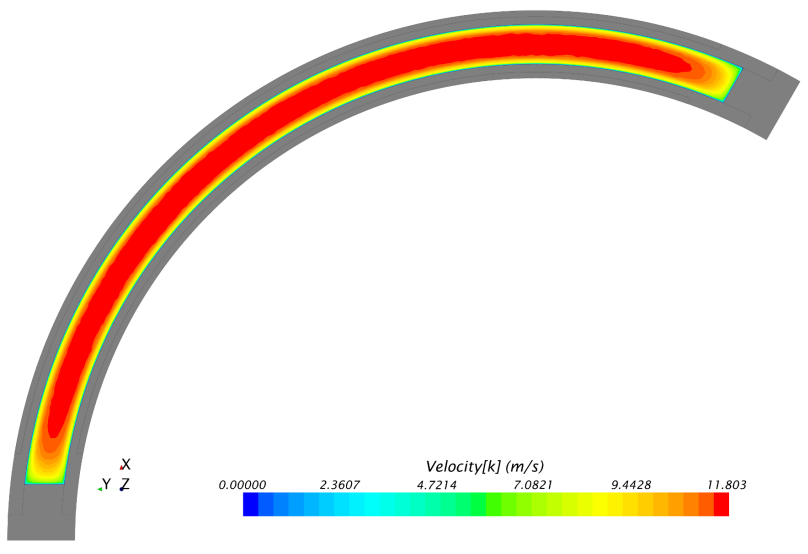

Figure 5: Velocity distribution in the hot channel on the $\mathrm{z}=0.315 \mathrm{~m}$ plane.

\subsubsection{Mass flow around the bottom end cap}

To demonstrate the mass flow in bottom end an axial velocity components are plotted on nine planes normal to the flow direction in Fig. 6. Planes are separated by $2.5 \mathrm{~cm}$ and the final plane is located $1.5 \mathrm{~cm}$ inside the fuel plates. For the same reason velocity axial components are plotted on the central plane perpendicular to the y-axis, see Fig. 7. An examination of the two figures reveals the same change of flow distribution discussed above.

In Fig. 7 it is observed that initially globally homogeneous flow is altered due to the geometrical changes/obstacles. After the geometry change $12.0 \mathrm{~cm}$ from the fuel plates flow is pended radially outwards. In the same place a flow field similar to backward-facing step flow with flow separation and later reattachment is observed. At $9.5 \mathrm{~cm}$ from the fuel plates a flow split pends flow additional radially outwards. After a flow split a low velocity region in the main flow towards the flow splitting wall is formed. In addition there is a recirculation near the flow splitting wall ending $6.0 \mathrm{~cm}$ from the fuel plates. Moreover the re-circulation areas can be seen in Fig. 6 in the fifth and in the sixth crosssectional planes.

There is a nearly stagnant flow field in flow passage that is separated from the main flow $17.7 \mathrm{~cm}$ and reconnected $12.0 \mathrm{~cm}$ from the fuel plates.

In conclusion, it is evident that the flow distribution in between the fuel plates arises from two main contributions: the natural flow distribution due to different hydraulic diameters in this geometry (without the influence of the bottom cap) and the jet effect.

\subsubsection{Mass flow around the top end cap}

For the top end part of the flow field analogue figures as described above are made, see Figs. 8 and 9 Fig. 8 has ten planes normal to the flow direction, separated by $2.0 \mathrm{~cm}$ and the first plane is located $0.8 \mathrm{~cm}$ inside the fuel plates.

In Fig. 9 one can notice three locations for the flow split ( $6.5 \mathrm{~cm}, 7.8 \mathrm{~cm}$ and $12.3 \mathrm{~cm}$ from the fuel plates) and two flow reunion locations $(9.75 \mathrm{~cm}$ and $14.0 \mathrm{~cm}$ from the fuel plates). At first, the flow in the main passage is pended radially outwards after the first two flow splits. Thereafter flow split and flow reunions pend the flow in the main passage radially towards the center.

At the outlet there are four surfaces: three main passages and one annulus. The mass flow is spread in a way that an annulus has $12.0 \%$ and a main passage $29.3 \%$ of the mass flow on average. In the both figures one can notice areas where the flow is nearly stagnant. 


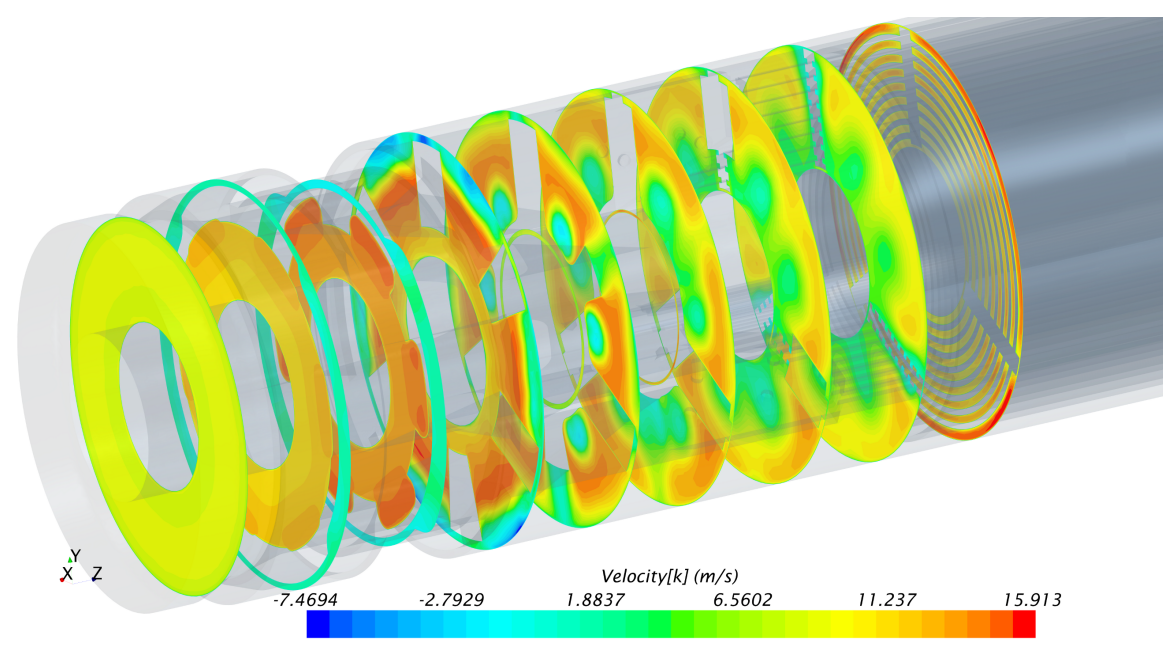

Figure 6: Bottom end cap surrounding flow field velocity axial components illustrated on multiple plane sections separated by $2.5 \mathrm{~cm}$.
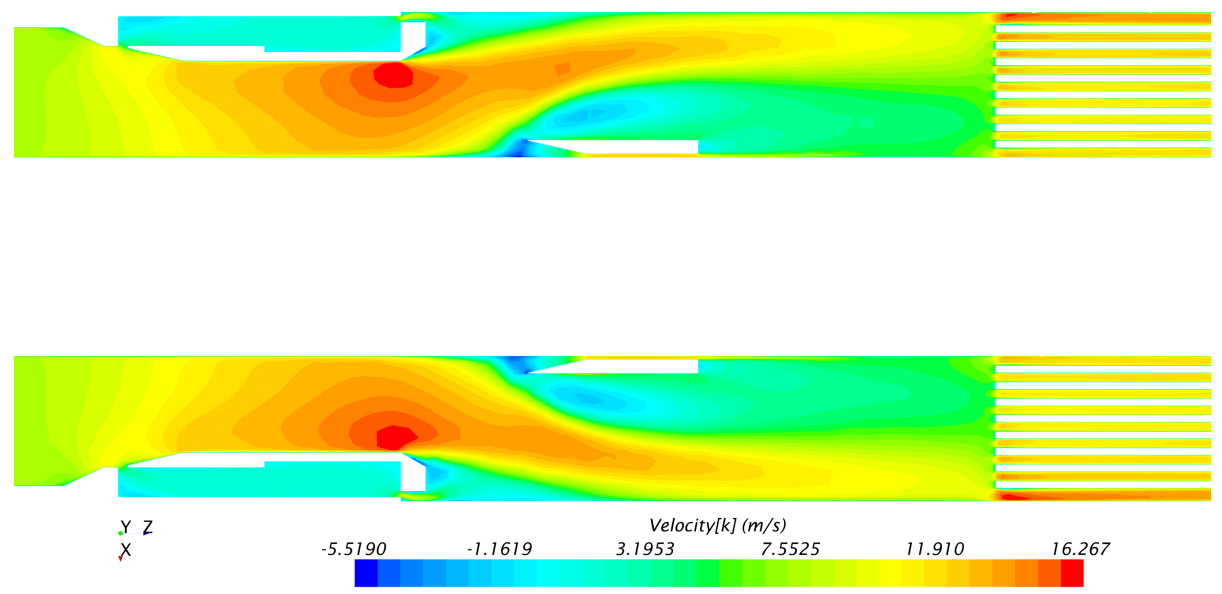

Figure 7: Velocity axial components around bottom end cap on the plate $y=0$.

\subsection{Pressure drop}

The pressure drop estimation was done by using the extended Bernoulli equation:

$$
p_{1}+\frac{1}{2} \rho_{1} v_{1}^{2}+\rho_{1} g h_{1}=p_{2}+\frac{1}{2} \rho_{2} v_{2}^{2}+\rho_{2} g h_{2}+\Delta p_{\text {loss }}
$$

where $g$ is the acceleration of gravity, $h$ the elevation and $\Delta p_{\text {loss }}$ is to account the losses:

$$
\Delta p_{\text {loss }}=\sum_{i}\left(f_{D, i} \frac{L_{i}}{D_{h, i}} \frac{1}{2} \rho_{i} v_{i}^{2}\right)+\sum_{j}\left(\xi_{j} \frac{1}{2} \rho_{j} v_{j}^{2}\right),
$$

where $\xi$ is the local loss coefficient. The first term in Eq. 14 describes the friction losses and the second term describes the local losses. Here index $i$ is referring to a $i$-th section with constant hydraulic diameter $D_{h, i}$ and index $j$ is referring to a $j$-th local loss.

The total pressure was measured in five different parts: the bottom end, transition from bottom end to the center, the center, transition from the center to the top end and the top end. Area-averaged parameters were utilized for calculating pressure drops. The width of the transition areas was picked to be $1 \mathrm{~mm}$. The areaaveraged pressure drops evaluated were the following: the bottom end $-52.3 \mathrm{kPa}$, the bottom end/center transition - 27.0 kPa, the center - $205.1 \mathrm{kPa}$, the center/top transition $-21.4 \mathrm{kPa}$ and the top end $-24.1 \mathrm{kPa}$. Transition drops are purely singular pressure drops and center drop is purely frictional, others represent the total pressure loss of the part. 


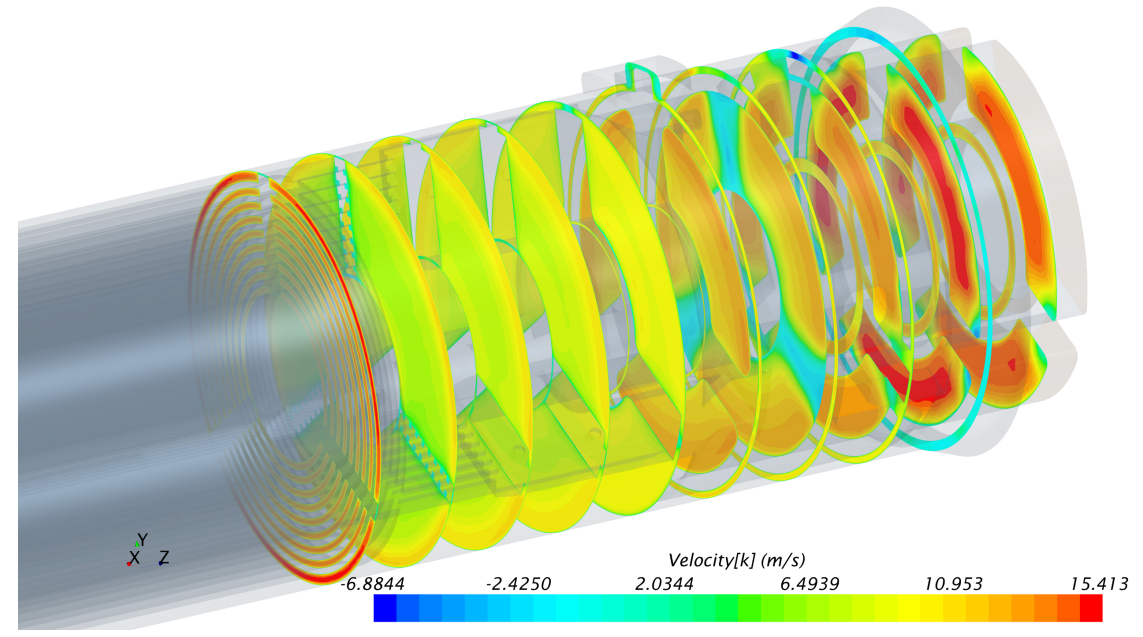

Figure 8: Top end cap surrounding flow field velocity axial components illustrated on multiple plane sections separated by $2.0 \mathrm{~cm}$.
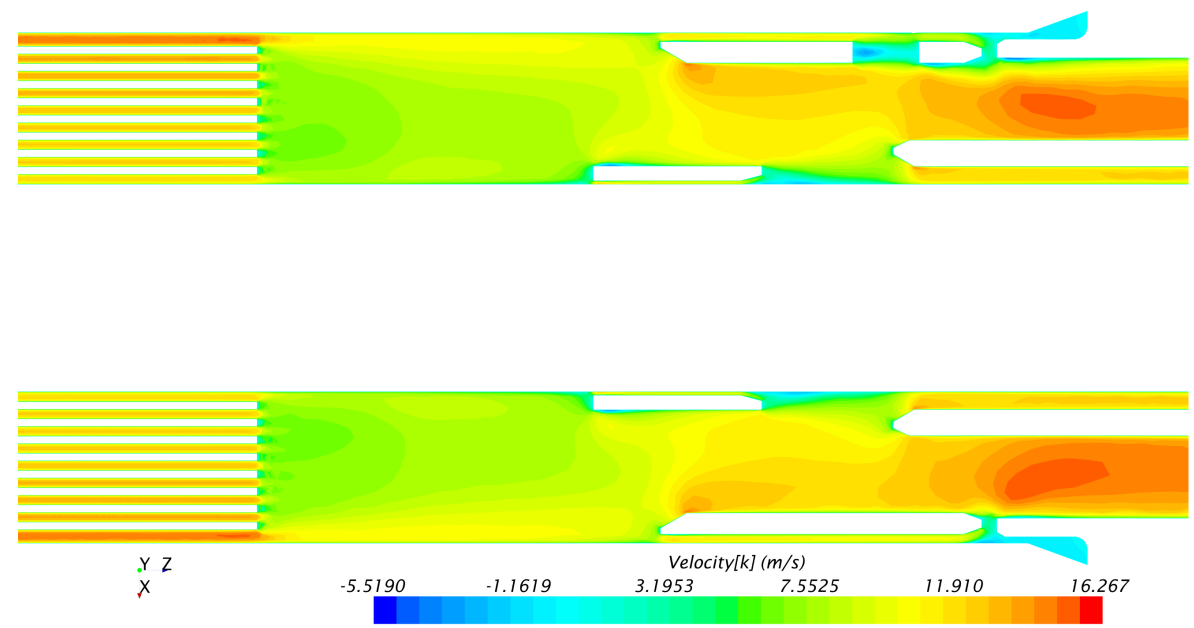

Figure 9: Velocity axial components around top end cap on the plate $y=0$.

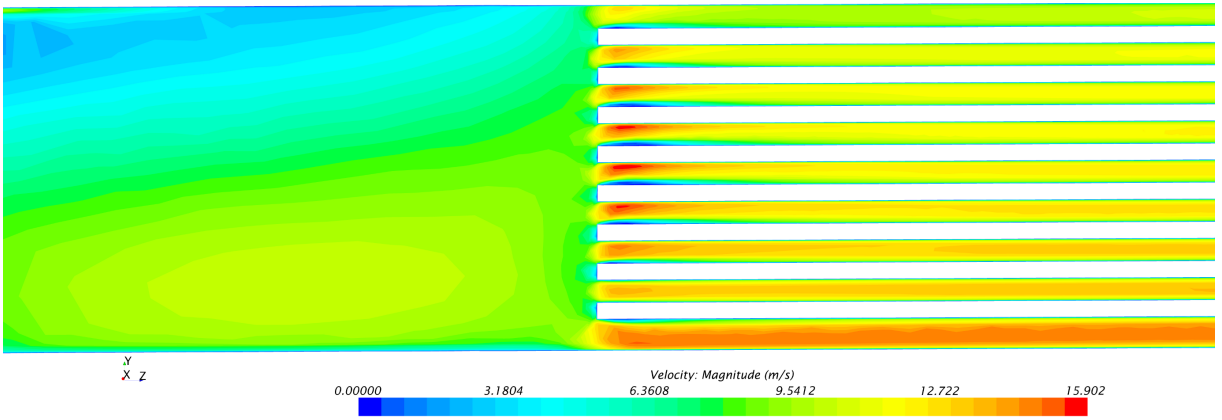

Figure 11: Velocity around bottom end cap in the center of hot sector on the plate $x=0$.

Next the Darcy friction coefficient in the hot channel in the case of the third geometry was evaluated along the axial direction locally after every $5 \mathrm{~mm}$ from the areaaveraged parameters and by using Eqs. 13 and 14 in a 


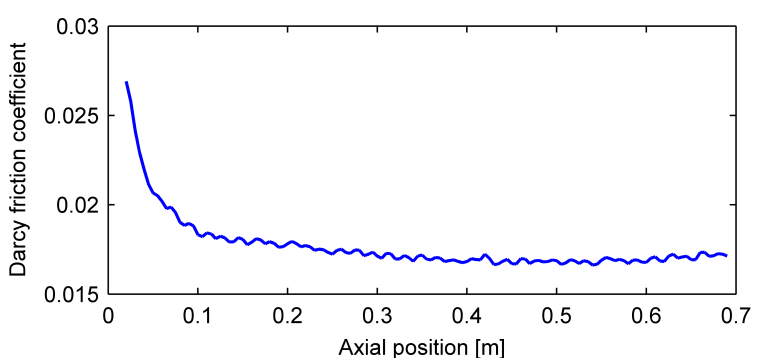

Figure 10: Darcy friction coefficient in the hot channel of the full fuel assembly geometry.

case of purely frictional pressure loss. Calculated Darcy friction coefficient axial position dependence is plotted in Fig. 10. Initial higher coefficient values can be explained by the flow field that is entering the fuel plates with an angle respect to the channels axial direction, see Fig 11 , and is related to the change of flow distribution.

\subsection{Temperatures and boundary heat flux in the hot channel}

Maximum temperatures obtained in the hot channel calculation are shown in Fig. 12 The maximum cladding temperature $T_{\text {cladding, } \max }=507.3 \mathrm{~K}$ and the maximum fuel temperature $T_{\text {fuel, } \text { max }}=582.7 \mathrm{~K}$ were below the melting temperatures $\left(T_{\text {cladding, } \text { melt }}=889 \mathrm{~K}\right.$, $\left.T_{\text {fuel,melt }}=918 \mathrm{~K}\right)$ and the overall integrity of the cladding with the fuel plates was ensured as well as the buckling was avoided ( $T_{\text {cladding }}<673 \mathrm{~K}$ ). Water reaches the maximum temperature $T_{\text {water, } \text { max }}=358.4 \mathrm{~K}$ $\left(T_{\text {water-outlet,mean }}=349.0 \mathrm{~K}\right)$ that is higher than the maximum temperature reached in the poison $T_{\text {poison, } \max }=$ $353.8 \mathrm{~K}$ and in the stiffener $T_{\text {stiffener, } \text { max }}=335.0 \mathrm{~K}$.

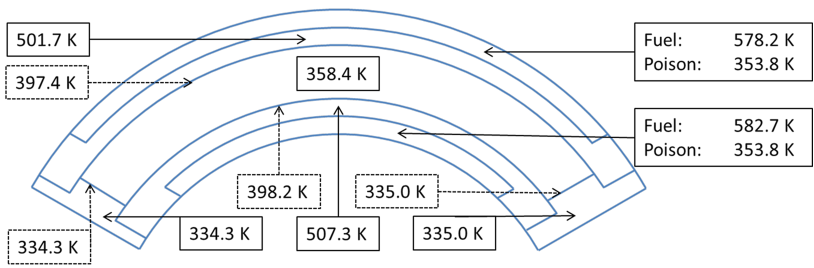

Figure 12: Schematic view of the maximum temperatures in the hot channel calculation. Dashed box marks the water-solid interface. Arrow shows only the part not the specific location.

Safety margin $(M)$ can be expressed in the following form:

$$
M=T_{l_{S A T}}+\Delta T_{S A T}-T_{w}>0,
$$

where $T_{l_{S A T}}$ is the liquid saturation temperature, $T_{w}$ is the wall temperature and $\Delta T_{S A T}$ is the wall superheat at which the fully developed subcooled boiling begins, which is given by Engelberg-Forster \& Greif correlation most suitable for JHR conditions (Engelberg-Forster and Greif, 1959):

$$
\Delta T_{S A T}=4.44\left(\frac{\Phi}{10^{4}}\right)^{0.385} \cdot\left(\frac{p}{10^{5}}\right)^{-0.23} \quad p<1 M P a,
$$

where the wall heat flux $\Phi$ is in $W / m^{2}$ and the pressure $p$ in $P a$.

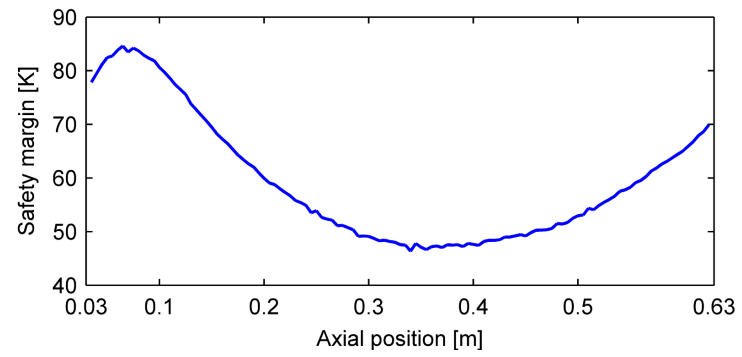

Figure 13: Safety margin in the hot channel in a fuel meat zone.

Safety margins along the axial direction in the zone on fuel meat was calculated and presented in Fig. 13 . A very conservative approach was used for obtaining minimum safety margin value in axial locations $0.5 \mathrm{~cm}$ apart. For this the minimum values of $T_{l_{S A T}}$ and $\Phi$ and the maximum values of $T_{w}$ and $p$ were obtained from the two heated walls and from the flow field between them. The minimum safety margin acquired was 46.4 $\mathrm{K}$.

Hot channel boundary wall heat flux is demonstrated in Fig. 14. The area where the heat flux is negative correspond to the influence of the fuel meat and the heat is given from wall to the liquid. On the other hand positive values correspond to the opposite direction heat transfer. Heat transfer from water to wall is dominant everywhere except from the areas of the fuel meat, however the heat flux is there around two orders less in magnitude and the heat transfer can be considered negligible.

The maximum volumetric heat source is located at $\mathrm{z}=$ $0.315 \mathrm{~m}$ and the azimuthal heat flux distribution on the inner wall (wall towards the center of the fuel assembly) to the water in the sector parallel to the fuel meat with or without axial and azimuthal conduction, see Fig 15.a). The heat flux without axial and azimuthal conduction is calculated from the power distribution, see Fig. 15.c). There is a small reduction, less than $4.8 \%$, in a heat flux in the central part $\left(90^{\circ}\right.$ in azimuthal angle) if the axial and azimuthal conduction is not taken into account. At the both ends of the fuel meat sections ( $4.35^{\circ}$ in azimuthal angle) the heat flux encoun- 


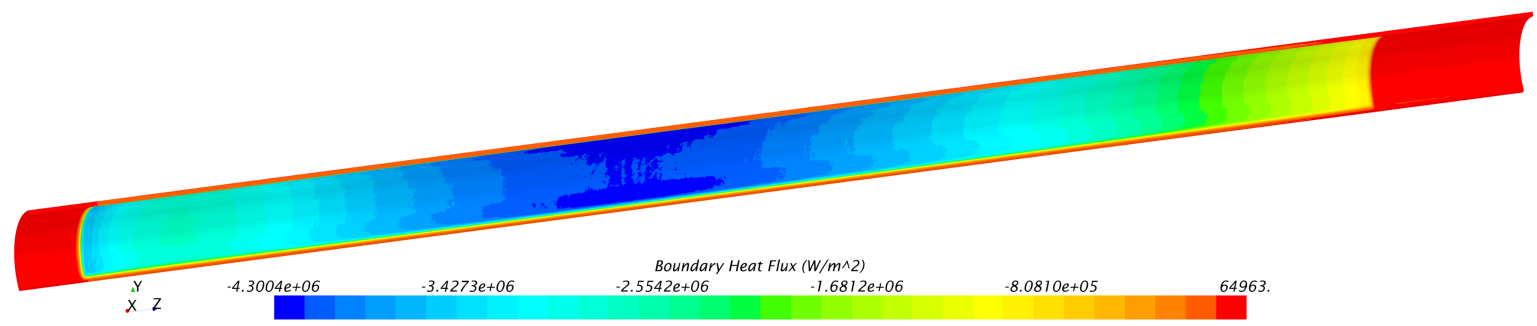

Figure 14: Boundary heat flux on the hot channel. Flow direction is from the left to the right and boundaries are seen from the center of the fuel assembly.

a)

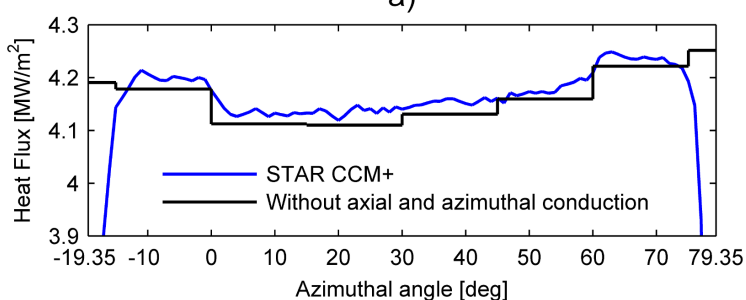

b)

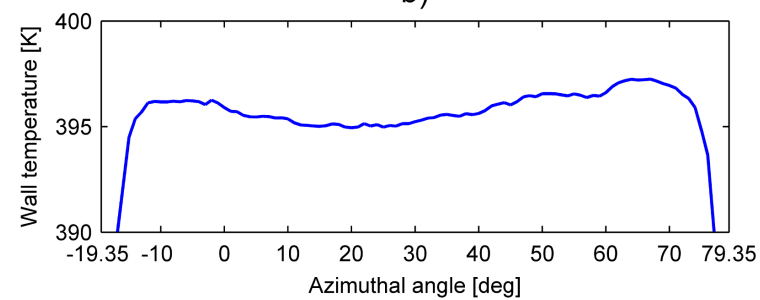

c)

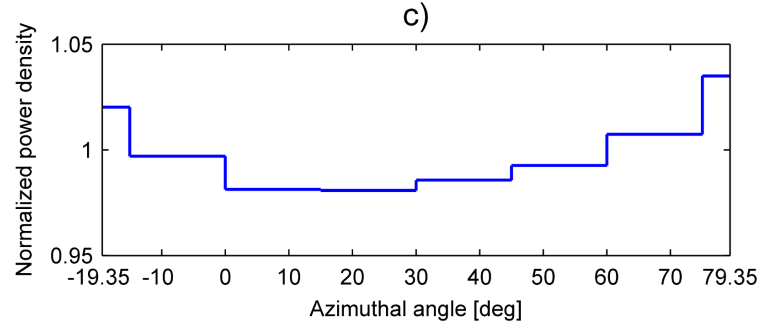

Figure 15: Hot channel calculation azimuthal dependent heat flux (a) and wall temperature (b) on the first fuel plate and the normalized power density (c) in the fuel meat at the height $\mathrm{z}=0.315 \mathrm{~m}$. All the parameters are plotted in the azimuthal interval that corresponds to the fuel meat location.

ters a noteworthy reduction caused by the conduction in the cladding towards the stiffeners. The azimuthal heat conduction can be found in Fig. 16, where temperature distribution is shown and the azimuthal heat conduction can be observed by the gradual temperature reduction in azimuthal direction in the cladding near the fuel meat.
The heat flux at the ends of the fuel meat sections is reduced by $52-55 \%$ of its value without axial and azimuthal conduction. Accordingly the wall temperature decreases 34-39 K by compared to the central "plateau". Similar findings discussed above have been reported in Tzanos and Dionne (2011) while investigating a BR2 fuel assembly geometry.

The azimuthal wall temperature distribution on the inner wall, see Fig 15. b), follows the azimuthal boundary heat fluxes distribution. In the central part the temperature is within $2.8 \mathrm{~K}$. The wall temperature as the heat flux has tendency to peak toward the edges, not in the center of the fuel plate.

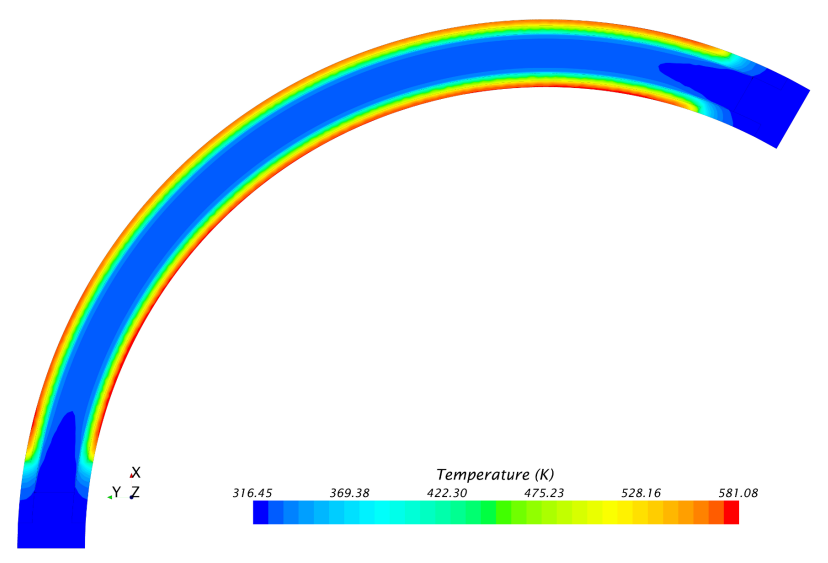

Figure 16: Temperature distribution in the hot channel and in the surrounding metal structures on the $\mathrm{z}=0.315 \mathrm{~m}$ plane.

\subsection{Heat transfer coefficient in the hot channel}

Convective heat transfer from heated wall into the incident fluid can be described by the Newton's law of cooling:

$$
h=\frac{\Phi}{T_{w}-T_{b}},
$$

where $h$ is the heat transfer coefficient and $T_{b}$ is the fluid bulk temperature. On the other hand $h$ can be expressed 
in terms of non-dimensional Nusselt number, $\mathrm{Nu}$, as follows:

$$
h=\frac{N u \cdot \lambda}{D_{h}} .
$$

There are several empirical $\mathrm{Nu}$ form correlations available for calculating $h$ in a case of a forced convection turbulent flows. Correlations evaluated in this paper are the following:

(i) Dittus-Boelter correlation for pipes (Dittus and Boelter, 1930):

$$
N u=0.023 \operatorname{Re}^{0.8} \operatorname{Pr}^{0.4}
$$

(ii) Modified Dittus-Boelter correlation for pipes proposed in Tzanos and Dionne (2011):

$$
N u=0.023 \operatorname{Re}^{0.8} \operatorname{Pr}^{0.4}\left(\frac{\mu_{b}}{\mu_{w}}\right)^{0.11},
$$

where $\mu_{b}$ is the bulk dynamic viscosity and $\mu_{w}$ is the dynamic viscosity evaluated at the wall temperature.

(iii) Sieder-Tate correlation for pipes (Sieder and Tate, 1936):

$$
N u=0.027 \operatorname{Re}^{0.8} \operatorname{Pr}^{1 / 3}\left(\frac{\mu_{b}}{\mu_{w}}\right)^{0.14} .
$$

(iv) Petukhov-Popov correlation for pipes (Petukhov and Popov, 1963):

$$
N u=\frac{\left(f_{D} / 8\right) \operatorname{RePr}}{1.07+12.7\left(f_{D} / 8\right)^{1 / 2}\left(\operatorname{Pr}^{2 / 3}-1\right)}\left(\frac{\mu_{b}}{\mu_{w}}\right)^{0.14}
$$

(v) Gnielinski correlation for pipes (Gnielinski 1976):

$$
\begin{array}{r}
N u=\frac{\left(f_{D} / 8\right)(R e-1000) P r}{1.07+12.7\left(f_{D} / 8\right)^{1 / 2}\left(P r^{2 / 3}-1\right)} . \\
\cdot\left[1+\left(\frac{D_{h}}{L}\right)^{2 / 3}\right]\left(\frac{P r}{P r_{w}}\right)^{0.11},
\end{array}
$$

where $P r_{w}$ is the Prandtl number evaluated at the wall temperature.

(vi) Gnielinski correlation for annulus (Gnielinski 1997):

$$
\begin{gathered}
N u=\frac{\left(f_{D} / 8\right)(\operatorname{Re}-1000) \operatorname{Pr}}{1.07+12.7\left(f_{D} / 8\right)^{1 / 2}\left(\operatorname{Pr}^{2 / 3}-1\right)} . \\
\cdot\left[1+\left(\frac{D_{h}}{L}\right)^{2 / 3}\right]\left[1-0.14\left(\frac{D_{\text {in }}}{D_{\text {out }}}\right)^{0.6}\right]\left(\frac{P r}{P r_{w}}\right)^{0.11} .
\end{gathered}
$$

In Eqs. 22, 23 and 24 the Darcy friction factor is obtained from Filonenko's correlation (Filonenko, 1954):

$$
f_{D}=\left(1.821 \log _{10} R e-1.64\right)^{-2} .
$$

By using Eq. 17 the mean axial location dependent heat transfer coefficient in the hot channel was evaluated by using the mean heated walls heat flux and the mean heated walls temperature and the liquid bulk temperature. Wall parameters were taken from the wall interfaces. Obtained $h$ is compared with ones estimated with the correlations described above. Figure 17 illustrates that the Gnielinski and the Petukhov-Popov correlations clearly overestimate and both Dittus-Boelter correlations underestimate the heat transfer coefficient. Except from the entrance of the channel the Sieder-Tate correlation slightly over-predict and under-predict $h$. Currently in thermal-hydraulic modeling of the JHR, see (Pegonen et al. 2014a), the Dittus-Boelter correlation is utilized for conservative estimation of $h$. In light of the present results modified Dittus-Boelter would give a less conservative results and the correlation could be improved when taken into account entrance effect as it is done in Gnielinski correlations. Nevertheless there is an additional project that investigates the improvement possibilities to find a new more reliable correlation.

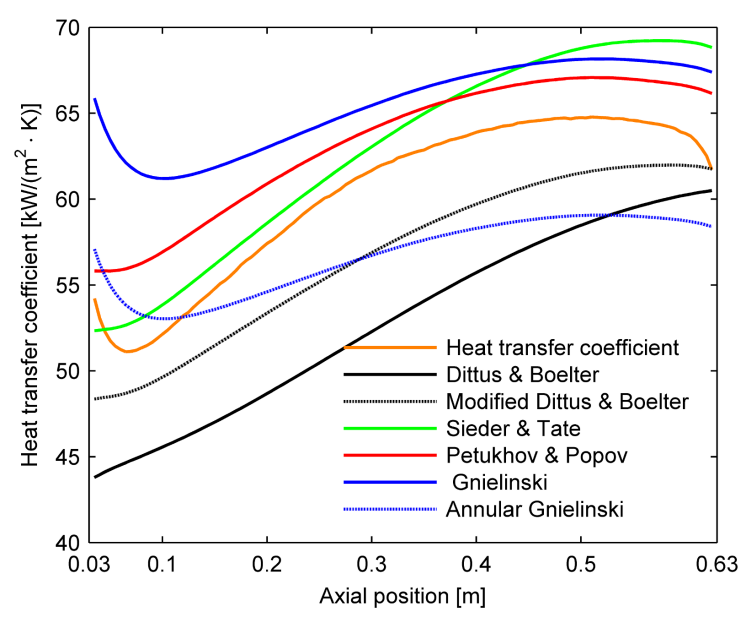

Figure 17: Heat transfer coefficient obtained in the hot channel compared with the correlations.

\section{Conclusions}

From the research that has been performed, it is possible to conclude that:

- Based on the results, the minimum safety margin under the nominal conditions is $46.4 \mathrm{~K}$ as well as the thermo-mechanical criterion clearly shows the absence of buckling in addition to the overall integrity of the cladding and the fuel plates. 
- The bottom end cap redirects the mass flow by reducing it through the first five channels and increasing it in the last four channels counting from the center of the geometry.

- The standard Dittus-Boelter correlation is found to be conservative under the JHR conditions. However based on the comparisons of the different heat transfer coefficient correlations to its value in the hot channel, a modified Dittus-Boelter correlation would be more appropriate choice for the safety analyses for giving a less conservative values while still under-predicting the heat transfer coefficient.

- The mass flow through the hot channel under cold condition is $0.919 \mathrm{~kg} / \mathrm{s}$ and under nominal conditions is $0.924 \mathrm{~kg} / \mathrm{s}$. There is a flow increase of $0.6 \%$.

- The Blasius correlation over-estimates the average mass flow rate in the second channel by $4.1 \%$ and the Colebrook correlation by $4.6 \%$.

- The total pressure loss in the modeled geometry is $3.3 \mathrm{bar}$ for the mass flow rate of $42.955 \mathrm{~kg} / \mathrm{s}$.

- Modeling central part of the hot channel (central $90^{\circ}$ in azimuthal angle) without axial and azimuthal conduction will lead to heat flux underestimation at the wall/liquid interface that is less than $4.8 \%$.

- The surface averaged temperature increase in the hot channel is $43.8 \mathrm{~K}$ and in the full hot fuel element is $29.4 \mathrm{~K}$.

\section{Future work}

The future research should concentrate on:

- Improving CATHARE2's core model presented in Pegonen et al. (2014a) by replacing the mean fuel assembly with more detailed core model. Current work results will be used as a benchmark calculation for the hot fuel element modeling.

- Study the effect of the turbulence model on the results. Instead of utilizing Reynolds-Averaged Navier-Stokes (RANS) realizable $k-\epsilon$ turbulence model, other RANS models or Large Eddy Simulation models should be considered.

- Employing the CFD model for simulating reactor design basic accident in transient mode.
The current CFD model could be improved by:

- Introducing the gamma heating into the metal parts of the assembly.

- Taking into account manufacturing tolerances and the operational effects on the fuel plates (oxidation, thermal expansion, swelling, etc...).

\section{Acknowledgement}

The financial support obtained from the Swedish Research Council through the DEMO-JHR project is gratefully acknowledged by the first author (R. Pegonen).

\section{References}

AREVA TA, 2011. Project RJH. Fuel element technical drawings.

ASM Aerospace Specification Metals, Inc., 2015. Aluminium 6061-t6; 6061-t651. http://asm.matweb.com/search/ SpecificMaterial.asp?bassnum=MA6061t6 accessed 6 January 2015.

Bignan, G., Lemoine, P., Bravo, X., 2011. Jules Horowitz Reactor: A New European MTR (Material Testing Reactor) Open to International Collaboration: Description and Status. Conference paper, RRFM 2011, Rome, Italy.

Boussinesq, J., 1877. Essai sur la théorie des eaux courantes. Mémoires présentés par divers savants à l'Académie des Sciences XXIII 1, 1-680.

CD-adapco, 2012. Best Practice Workshop: Heat Transfer. Workshop presentation, STAR South East Asian Conference 2012, Singapore.

CD-adapco, 2013. STAR-CCM+ Version 8.02 User Guide.

CEA, 2013. The Jules Horowitz Reactor (JHR). http://www . cad. cea.fr/rjh accessed 28 October 2014.

Dittus, F. W., Boelter, L. M. K., 1930. Heat transfer in automobile radiators of the turbular type. University of California Publications in Engineering 2, 443-461.

Dupuy, J., Perotto, G., Ithurralde, G., Leydier, C., Bravo, X., 2005. Jules Horowitz Reactor General layout, main design options resulting from safety options, technical performances and operating constraints. Joint meeting paper, TRTR-2005/IGORR-10, Gaithersburg, Maryland, USA.

Engelberg-Forster, K., Greif, R., 1959. Heat Transfer to a Boiling Liquid: Mechanism and Correlation. Transactions of the ASME, Journal of Heat Transfer 81, 43-53.

Filonenko, G. K., 1954. Hydraulic resistance in pipes. Teploenergetika 1 (4), 40-44.

Gallegos-Muñoz, A., Uzárraga-Rodriquez, N. C., Elizalde-Blancas, F., 2012. Conjugate heat transfer in ribbed cylindrical channels. In: Kazi, S. N. (Ed.), An Overview of Heat Transfer Phenomena. InTech, Rijeka, Ch. 16, pp. 469-496.

Gnielinski, V., 1976. New Equations for Heat and Mass Transfer in Turbulent Pipe and Channel Flows. Int. Chem. Eng. 16, 359-368.

Gnielinski, V., 1997. Wärmeübertragung im konzentrischen Ringspalt und im ebenen Spalt. In: VDI Wärmeatlas, 8. Auflage. SpringerVerlag, Berlin, pp. S Ga 1-GA 9.

Iracane, D., Chaix, P., Alamo, A., 2008. Jules Horowitz Reactor: a high performance material testing reactor. Comptes Rendus Physique 9, 445-456. 
Kuron, M., 2015. 3 Criteria for Assessing CFD Convergence. http://www.engineering.com/DesignSoftware/ DesignSoftwareArticles/ArticleID/9296/ 3-Criteria-for-Assessing-CFD-Convergence.aspx accessed 13 January 2015.

NRC, 2001. Appendix A. Material Properties for COBRA-SFS Model of TN-68 Cask. http://pbadupws.nrc.org/docs/ML0524/ ML052490246.pdf accessed 6 January 2015.

Pegonen, R., Bourdon, S., Gonnier, C., Anglart, H., 2014a. A review of the current thermal-hydraulic modeling of the Jules Horowitz Reactor: A loss of flow accident analysis. Nucl. Eng. Des. 280, 294-304.

Pegonen, R., Edh, N., Angele, K., Anglart, H., 2014b. Investigation of Thermal Mixing in the Control Rod Top Tube Using Large Eddy Simulations. Journal of Power Technologies 94 (1), 67-78.

Peric, M., 2004. Flow simulation using control volumes of arbitary polyhedral shape. ERCOFTAC Bulletin 62

Petukhov, B. S., Popov, V. N., 1963. Theoretical Calculation of Heat Exchange in Turbulent Flow in Tubes of an Incompressible Fluid with Variable Physical Properties. High Temp. 1 (1), 69-83.

Pouchin, B., 2013. Private communications.

Shih, T.-H., Liou, W. W., Shabbir, A., Yang, Z., Zhu, J., 1994. A new k-epsilon eddy viscosity model for high reynolds number turbulent flows: Model development and validation. Technical report, NASA TM 106721, NASA Lewis Research Centert, Cleveland, $\mathrm{OH}$, United States.

Sieder, E. N., Tate, G. E., 1936. Heat Transfer and Pressure Drop of Liquids in Tubes. Ind. Eng. Chem 28, 1429-1436.

Sireta, P., 2014. Private communications.

Tzanos, C. P., Dionne, B., May 2011. Computational Fluid Dynamics Analyses of Lateral Heat Conduction, Coolant Azimuthal Mixing and Heat Transfer Predictions in BR2 Fuel Assembly Geometry. Tech. rep., Argonne National Laboratory, ANL/RERTR/TM-1121.

Wilcox, D. C., Nov. 2006. Turbulence Modeling for CFD, 3rd Edition. DCW Industries, California, USA 